\title{
The Usage of Laser Doppler Flowmetry for Evaluation of the Efficiency of Ozone-Containing Drugs for External
}

\section{Use}

\author{
O. Grechkanyova, O. Bitkina, S. Peretyagin, P. Peretyagin, I. Gabasov and P. Razheva \\ Nizhny Novgorod State Medical Academy, the Volga District Federal Medical Research Institution, the Russian Association of \\ Ozone-Therapists, the "Alexandria” Clinic, Nizhny Novogorod 603006, Russia
}

\begin{abstract}
Ozone-containing drugs for external use are the new trend in applying of medical ozone-oxygen mixture. For the last few years the majority of manufacturer countries have produced wide lines of ozone-containing cosmetics, which were presented in various ozone therapeutic congresses. Its properties are used in dermato-cosmetology for correction of the changes associated with aging, promoting regeneration, shortening the recovery period after surgeries or chemical peelings. The article presents the results of LDF (laser Doppler flowmetry) study of skin's blood dynamics in response to applying cosmetic gels containing different amounts of active oxygen in the form of ozonides, Comparative analysis of the three-patient groups allowed us to draw a conclusion about the accumulating stimulating effect of the “Ozodermis” 10\% cream on skin's microcirculation, which makes it perspective for use as in healthy people for improving one's skin condition, as well as in people suffering from diseases, the key roles in pathogenesis of which are disorders in the skin's microcirculation (exampli gratia: vasculitis, severe forms of atopic dermatitis).
\end{abstract}

Key words: LDF, ozone therapy, dermatology, cosmetics.

\section{Introduction}

Currently the ozone containing drugs for external use are widely applied in dermato-cosmetology for control over the changes associated with aging, promotion of regeneration processes, and shortening the recovery period after surgeries and chemical peelings [1]. The local and systemic reactions of an organism in response to external application of cosmetic ozone-containing gels have been studied on laboratory animals [2]. In case of skin diseases or trauma there are numerous therapeutic effects of applying the ozone-containing drugs for external use, such as: bactericidal, fungicidal, virucidal, antioxidant effects, wound or ulcer surface cleaning, promotion of regeneration and acceleration of the epithelialization processes, normalization of the immune response, activation of peripheral microcirculation. In the last

Corresponding author: Oxana Bitkina, Ph.D., research fields: ozone therapy in dermatology. few years the majority of the manufacturer countries produced wide product lines of ozone-containing cosmetics, which are being presented in various ozone therapeutic congresses: "Ozonrelive” (Italy), “Ozonoaqua”, “Ozolife” and “Ozono D’Or” (Spain), “Balmozon OzonizedOil” and “Ozon Yagı” (Turkey), “Oleum3” and "Nutraozone Ozoneactive” (USA); “Trioximed” (Mexico). The Russian ozone-containing drugs production is represented by the "Ozone Beauty" line, Medozons, Nizhny Novgorod: Ozodermis 10\% (30 mL) cream containing ozonides, Ozodermis 5\% (50 mL) cream containing ozonides, Ozodermis 3\% (80 mL) cream containing ozonides; the "Otry" line, which includes hair masks, creams and ozonatied olive oil with the high peroxide numbers of 6,000 and 12,000 units (Medozons, Nizhny Novgorod). The Mezodons Moscow Company's lines Aliying Ozone are present at the market for over 20 years.

Ozone-containing drugs become one of the current trends in therapy of dermatoses and cosmetic skin 
defects, so the pathogenetic rational is needed. Thus a research has been carried out. The aims were to study the dynamics of changes in blood microcirculation in response to applying cosmetic gels, containing different amounts of oxygen in the form of ozonides, in human.

The modern and most efficient method of assessing the status of microcirculatory blood flow is LDF (laser Doppler flowmetry). It is widely used in various fields of theoretical and practical medicine. LDF is used to diagnose the condition of the investigated object in health and none, and also to evaluate treatment efficacy [3]. IR (Infrared) imaging and LDF are used to study IR effects, mediated by vascular reactions, in volunteers with periodic unilateral arteriovenous occlusion of one of the fingers.

There are known cases of application of the LDF method in dermatological practice. The use of LDF in the study of microcirculation regulation system and aging mechanisms has been described. As a result of studying the peripheral blood flow parameters in healthy individuals of different age groups, simplification and increased ordering degree of the microcirculatory system were detected [4].

Y. A. Makedonova, I. V. Firsova, S. V. Poroisky, D. V. Mikhalchenko [5] with the help of LDF have studied microcirculatory features in healthy people and in patients with lichen planus. According to LDF, the deterioration of microcirculation is observed both in the affected area and in the clinically intact mucosa of the symmetric regions. Thus, LDF in combination with clinical data makes it possible to assess the affected tissue condition objectively.

LDF allows estimating the perspective of various treating methods of patients with atrophic skin lesions authentically, namely: lichen sclerosis, soldered skin scars. LDF-grams reflect the improvement of the active functioning capillaries number in the epidermis of patients after the reconstructive therapy [6].

When studying the scalp microcirculation in patients with diffuse alopecia using the LDF method, increased neurogenic and endothelial components of the vascular tone were revealed. After treatment the capillaries blood flow has improved, LDF values have been normalized [7].

LDF data confirm the therapeutic efficacy of a combined treating method of patients with alopecia areata. When measuring the microcirculation in patients with alopecia areata increased arteriolar tone and stagnation phenomena in the venular part were revealed. Against the background of complex therapy, the positive dynamics of the main microcirculatory indicators in the hair loss focuses was noted [8].

Microcirculatory defects of a spastic stagnant type in patients with atopic dermatitis were revealed. As a result of treatment, a slowdown in the skin inflammatory changes is observed, that is confirmed by the increased microcirculatory rates, evaluated by LDF [9]. The represented data are correlated with earlier studies on the hypoxia presence in patients with severe forms of atopic dermatitis, characterized by a low oxygen tension in the lesions and unaffected skin [10], that makes application of methods aimed at microcirculatory disorders correction in the complex therapy of atopic dermatitis, in particular, the method of adaptation to periodic pressure chamber biopsy [11]; ozonotherapy [12]; infusions of reamberin solution [10] promising.

The features of microcirculatory disorders in patients with psoriasis according to LDF are described by D. A. Adyrkhaeva, E. V. Natarova, N. A. Ryumkina [13]. Psoriasis decreased activity of the neurogenic blood flow component and the myogenic and endothelial components enhancement are noted. The results of LDF allow selecting appropriate methods of treatment based on pathophysiologic mechanisms. Thus, a certain experience of LDF-evaluation of microcirculation disorders in a number of dermatoses has been accumulated.

LDF has a special value for evaluating the therapeutic efficacy of ozone therapy techniques, both systemic and local, since the therapeutic application of 
the medical ozone-oxygen mixture is based on the increased deformability of erythrocytes and the improvement of oxygen release in tissues, so-called O. Rokitansky's mechanism (Fig. 1) [14].

By now the methodology of system ozonotherapy methods application for treatment of a number of dermatoses has been formed [15, 16, 17]. There is an experience of using LDF to evaluate the ozone therapy effectiveness in dermatology. A. G. Kulicov [18] has studied the effect of the combined ozone therapy on the microcirculatory blood flow condition in patients with eczema. In the course of the study, a decrease in clinical manifestations of the disease and a pronounced positive dynamics of microcirculation indicators were observed. In addition, in the correction of microcirculation disorders with eczema, a more significant role was played by general (systemic) ozonotherapy. Besides, general (systemic) ozonotherapy has played more significant role in the correction of microcirculation disorders in patients with eczema.

\section{Materials and Methods}

LDF is a noninvasive method of blood microcirculation study, which is probing a tissue with laser and following analysis of the received data.

It is based on the Doppler Effect phenomenon, which postulates that frequency of the radiation, perceived by an observer, changes depending on movement of the source or the observer himself. In case of the flowmetry it means that, after being reflected from erythrocytes, the laser radiation changes its frequency proportionally to the cells movement speed, allowing us to estimate the quality of microcirculation in the region. Herewith, compared to ultra-sound methods using the same idea background, usage of laser allows getting a signal of wider amplitude from individual erythrocytes in even thinner tissue layers up to $1 \mathrm{~mm}$ [19].

Aggregate of signals from every erythrocyte of the studding area forms an averaged index. We are able to estimate the quality of perfusion in the region by processing the aggregate data by formula LDP = $\mathrm{KN}_{\mathrm{er}} \mathrm{V}_{\mathrm{av}}$ (where LDP-Laser Doppler Perfusion, $\mathrm{K}$ - the coefficient of proportionality $(\mathrm{K}=1), \mathrm{N}_{\mathrm{er}}$-the erythrocytes' number, $\mathrm{V}_{\mathrm{av}}$-the average erythrocytes' speed). LDP stands for changes in perfusion of the studded region and is directly proportional to the number of erythrocytes and its speed in the region. LDP cannot be represented in any absolute units, such as $\mathrm{mL} / \mathrm{sec} / \mathrm{mm}^{3}$, because of the devise's inability to evaluate the Brownian motion in blood-data presented in such units would be simply unreliable [20].

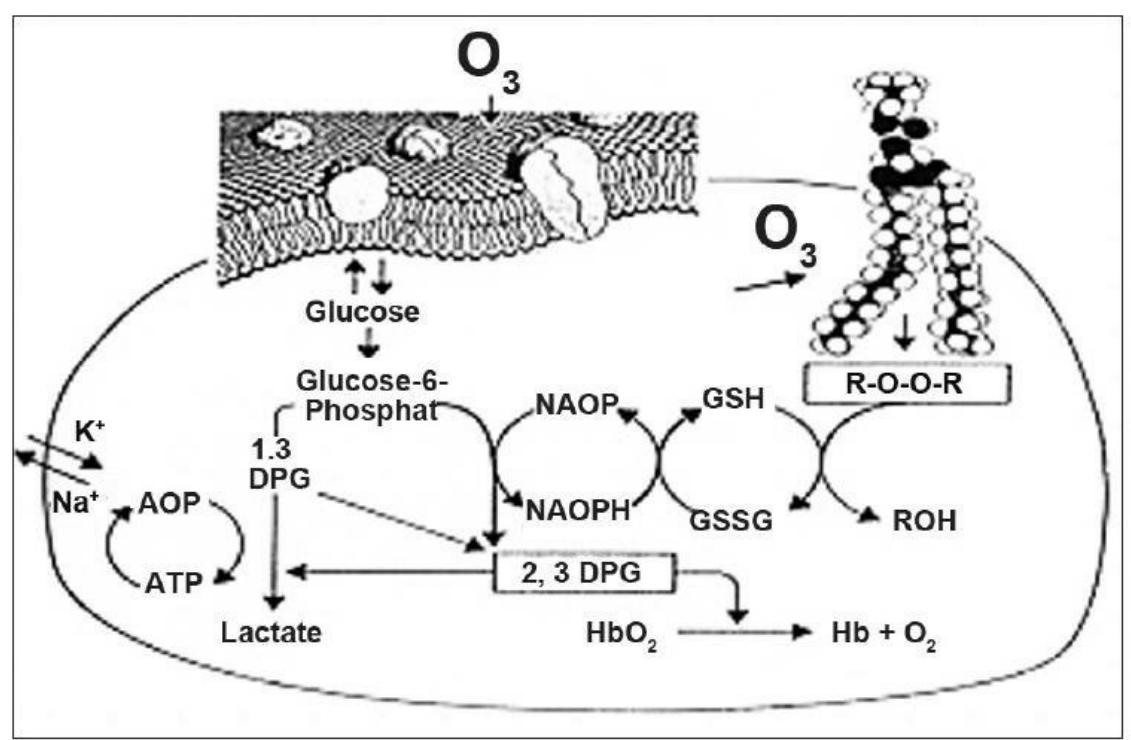

Fig. 1 “Erythrocyte” O. Rokitansky’s mechanism. 


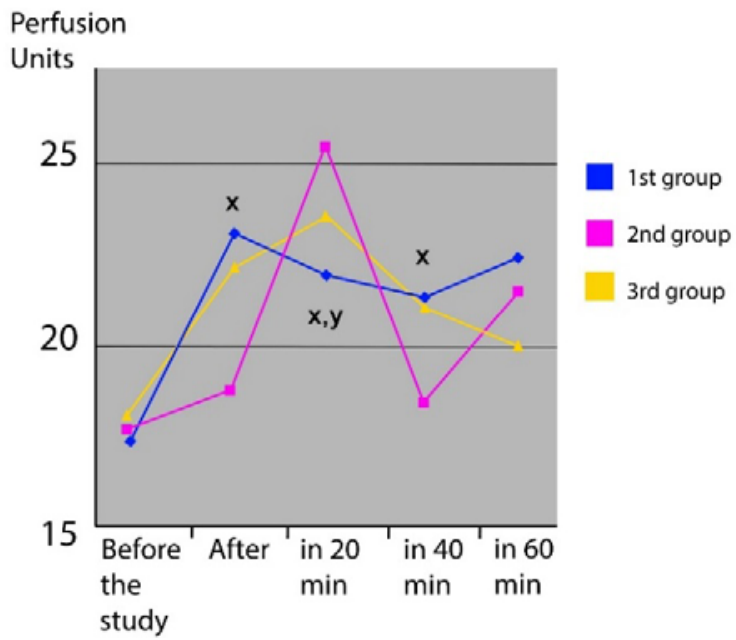

Fig. 2 Influence of the different methods of impact on general skin's microcirculation rate $(x$-reliability of differences $(p<0.05)$ of the 3rd group index related to 1st group index, $y$-reliability of differences $(p<0.05)$ of the 3rd group index related to 2 nd group index).

Thus for the sake of estimation special relative "perfusion units" are used, which characterize the change of blood flow in unit of time in the probed area [21].

The study was carried out on 18 patient subjects, who were from 35 to 65 years old. The standard conditions included the room's temperature of 23-25 ${ }^{\circ} \mathrm{C}$ and 20-minute rest lying before the studies to get accustomed to the conditions. The participants were nearly healthy people, who consulted a cosmetologist to improve the skin's condition. They were divided into three groups with 6 people each. The 1st group, after some cleaning and degreasing, was to undergo glycol peeling (glycol acid gel 52.5\% $\mathrm{pH}=2.0$ ) with exposition of 5 minutes and further neutralization with neutralizing alkaline solution (sodium bicarbonate $2.5 \%)$. The 2nd group underwent the same procedure of applying glycol peeling (glycol acid gel 52.5\% pH = 2.0) with exposition of 5 minutes and alkaline solution neutralizing afterwards (sodium bicarbonate 2.5\%), but then the $5 \mathrm{~cm}$ diameter and $2 \mathrm{~mm}$ thick round-shaped application of the "Ozodermis" cream was applied to each participant's forehead for 10 minutes. The 3rd group went straight through applying the $5 \mathrm{~cm}$ diameter and $2 \mathrm{~mm}$ thick round-shaped application of the "Ozodermis" cream on forehead with exposition of 10 minutes without previous peeling.

\section{Results and Discussions}

The results were estimated by LDF of the central forehead area. First, the area was probed before anything was applied in all the patients. Then it was probed after peeling in the 1st group of patients, and after the cream's exposition in 2nd and 3rd groups. In 20, 40 and 60 minutes after the procedures it was probed again in all the groups. One month later all the patients went through LDF probing of the same area once again. During that month the patients of the 3rd group were using "Ozodermis" $10 \%$ cream as a skin care product applying it every morning and evening, while the rest continued using their regular skin care products (ozone non-containing creams of different brands for the post-peeling period). Each study lasted 400 seconds and was provided by means of $3 \mathrm{~mm}$ diameter probe in the red channel of laser radiation (wavelength $0.63 \mathrm{mcm}$, probing depth about $0.8 \mathrm{~mm}$ ), and in infrared channel (wavelength $1.15 \mathrm{mcm}$, probing depth about $1.6 \mathrm{~mm}$, also including deeply located microvessels). The analysis of the received LDF data allowed us to evaluate the area's state of skin microcirculation in perfusion units, as well as to estimate the microcirculation's control elements' quantity: the active control factors (endothelial, myogenic and neurogenic mechanisms of the vessels' wideness regulation) and the passive control factors (respiratory and cardiac mechanisms). Statistical processing of the data was carried out by Microsoft XL. The skin's response to application of the cream did not differ in all the groups (Fig.2).

However, the second study 30 days after reviled reliable microcirculation's rate increase of $25 \%$ in all patients of the 3rd group (Fig.3).The increase mainly is due to myogenic and respiratory components (the myogenic component increased by 53\% compared to the initial, vascular by 24\%). Subjectively all the 3rd 
group patients have noticed improvements in the skin's look, relief and color.

The current research is one of the first attempts of laboratory monitoring of applying of ozone-containing drugs for external use in clinical conditions, and it needs comparison with the data of skin's functional parameters (such as moisturizing, fat content, elasticity, erythema and pigmentation). Our laboratory has begun this correlation analysis of the microcirculation indexes and functional characteristics of skin's state by means of “Multi Skin Test Center MC 1000 Standard” devise.

\section{Conclusions}

The study found accumulative stimulating effect of the "Ozodermis" $10 \%$ cream on the skin microcirculation, which makes it perspective to use for skin's state improvement in healthy people, as well as for treatment of patients suffering from conditions associated with malfunction of the skin microcirculation (vasculitis, severe forms of atopic dermatitis).

\section{References}

[1] Bitkina, O. A., and Sokolov, S. A. 2013. "The Perspectives of Applying Ozone-Containing Drugs for External Use in Dermatology.” Medicinsky Almanach Magazine 3 (27).

[2] Bitkina, O. A., Peretyagin, S. P., Solovyova, A. G., Grechkanyova O. A., Martusevich, A. K., Bugrova, M. L., Peretyagin P. V., and Prodanets N. N. 2016. "The Study of Local and Systemic Reactions of an Organism in Response to Applying Cosmetic Gels Containing Ozonides.” Bioradicals and Antioxidants 2 (1): 32-9. http://www.ozonetherapy.ru/izuchenie-mestnyh-i-sistemn yh-reaktsij/.

[3] Davydova, A. V., Morrison, A. V., Utts, S. R., Meglinsky, I. V., and Lygachev, V. V. 2012. "Evaluation of Facial Skin's Microcirculatory Vessels State by Laser Doppler Flowmetry Method." Saratov science-medical magazine 8 (2): 615-21.

[4] Tankanag, A. V., Tikhonova, I. V., and Chemeris, N. K. 2006. "Non-linear Analysis of the Changes of Dynamics of Peripheral Blood Flow in the Process of Aging." Vestnik Novych Medicinskych Technologiy 13 (3): 96-8.

[5] Makedonova, Y. A., Firsova, I. V., Poroisky, S. V., and Mikhalchenko, D. V. 2016. "Analyze of Capillary Blood
Flow Index in Patients Suffering from Red Flat Leafworm of the Oral Cavity Mucosa.” Vestnik VolgGMU 1 (57): 65-7.

[6] Psavok F. A. 2009. "The Role of Psammotherapy and Sea Procedures in Recovery Treatment of Atrophic Skin Lesions Patients.” Vestnik novych medicinskych technologiy 16 (4): 115-7.

[7] Tkachenko, S. B., Olisova, O. Y., Pashchenko, E. Y., and Buchaeva, Z. K. 2013. "The Therapy of Diffuse Alopecia with Use of Intradermal Injections of Group B Vitamins and Cystine B6 Complex.” The Russian Magazine of Skin and Venereal Diseases 3: 58-61.

[8] Monakhov, S. A., Lyashenko, A. Y., Korchazhkina, N. B., Kruglova, L. S., Shabliy, R. A., Perminova, M. A., and Olisova, O. Y. 2012. "Combined Pharmaco-Physiotherapeutic Method in the Treatment of Focal Alopecia." The Russian Magazine of Skin and Venereal Diseases 3: 45-6.

[9] Kozulin, E. E., and Kozulin, E. A. 2015. "Fitomineral Corneo Therapy in Rehabilitation of Children with Atopic Dermatitis.” The Far East Medical Magazine, 58-60.

[10] Kulicova, O. D. 2001. "The Role of Hypoxia in Development of Antioxidant Defense Disorders in Children with Atopic Dermatitis and Its Correction with Reamberin.” Abstract Dissertation M.Sc. Moscow, pp. 16-7.

[11] Bannikov, V. K. 1998. "The Treatment and Rehabilitation of Eczema and Atopic Dermatitis Patients by Method of Adaptation to Periodic Pressure Chamber Hypoxia.” Abstract Dissertation M.Sc. Moscow, p. 34.

[12] Ivanova, O. A. 1998. "The Usage of Ozone in Neurodermatitis Patients, Considering the Immune Status, Pro- and Antioxidant Systems." Abstract Dissertation M.Sc. Moscow, p. 16.

[13] Adyrkhaeva, D. A., Natarova, E. V., and Ryumkina, N. A. 2007. "The Features of Laser Doppler Flowmetry Data in Cases of Psoriasis.” Vestnik Novych Medicinskych Technologiy 14 (1): 120-2.

[14] Rokitansky, O. 1982. "Klinik und biochemic der ozon therapy.” Hospitalis 52: 643-711.

[15] Bitkina, O. A. 2010. "The Scientific Rationale of Applying the Medical Ozone-Oxygen Mixture for Treatment Rosacea and Acne Vulgaris at the Basis of Dynamics of Indexes of Lipid Peroxidation, Antioxidant System and Oxidative Modification of Proteins.” Abstract Dissertation Ph.D. Moscow, p. 48.

[16] Baytyakov, V. V. 2012. "The Pathogenetic Rationale of Extracorporeal and Intravascular Hemocorrection Methods in Therapy of Patients Suffering from Psoriasis Vulgaris.” Abstract Dissertation Ph.D., Ekaterinburg, p. 38.

[17] Koshelyova, I. V. 2013. “Oxygen-Ozone Therapy of 
The Usage of Laser Doppler Flowmetry for Evaluation of the Efficiency of Ozone-Containing Drugs for External Use

Chronical Immune-Depended Dermatoses.” Abstract Dissertation Ph.D., Moscow.

[18] Kulicov, A. G. 2012. "Ozonetherapy: Microdynamic Aspects.” Physiotherapy, Balneology and Rehabilitation 3: 3-7.

[19] Fagrell, B. 1994. Problems Using Laser Doppler on the Skin in Clinical Practice, Laser Doppler. London, Los
Angeles, Nicosia: Med-Orion Publishing Company.

[20] Bracic, M., 1999. "Physics of the Human Cardiovascular System.” Contemporary Physics 40 (1): 31-5.

[21] Borgos, J. 1994. Principles of Instrumentation: Calibration and Technical Issues. Laser Doppler. London, Los Angeles, Nicosia: Med-Orion Publishing Company, pp. 3-16. 